\title{
The parasite-induced surfacing behaviour in the cockle Austrovenus stutchburyi: a test of an alternative hypothesis and identification of potential mechanisms
}

\author{
K. N. MOURITSEN* \\ Department of Zoology, University of Otago, P.O. Box 56, Dunedin, New Zealand
}

(Received 3 Fuly 2001 ; revised 9 October and 4 December 2001 ; accepted 4 December 2001)

S U M M A R Y

The New Zealand cockle Austrovenus stutchburyi, whose foot is commonly infected by the digenean trematode Curtuteria australis (Echinostomatidae), is often found heavily infected and unable to burrow on the sediment surface of tidal flats. This has been interpreted as a Curtuteria-manipulation with the purpose of increasing the transmission of the parasite to shorebirds acting as final hosts. Using a field-experimental approach the alternative hypothesis was tested, that surfacedwelling cockles, caught on the surface for other reasons than parasites, accumulate larval C. australis at a higher rate than buried cockles. During the 3-month experiment, larval trematodes accumulated with a rate of approximately $0 \cdot 5$ metacercariae/day in both surface and buried cockles. The result strengthens the manipulation hypothesis indirectly by rejecting the alternative hypothesis. The metacercariae were unevenly distributed along the cockle-foot, with about 4 times as many cysts being found in the tip than in either the mid or hind part of the foot. In light of existing knowledge of the burrowing behaviour and apparatus in bivalves, and a negative relationship between foot mobility and infection intensity, it is suggested that $C$. australis manipulates its host through a mechanical obstruction of foot muscles and the dynamic hydrostatic skeleton, both necessary for successful burrowing.

Key words: Austrovenus stutchburyi, behavioural manipulation, Curtuteria australis, infection rate, manipulative mechanism, site selection.

\section{INTRODUCTION}

Infection by larvae of helminth parasites with complex life-cycles is often associated with altered host behaviour. This is usually interpreted as an adaptive parasite-induced behavioural change with the purpose of facilitating transmission of the parasite to the next host in the life-cycle. In some cases it seems beyond reasonable doubt that the behavioural change is in fact a parasite adaptation produced by natural selection, either because the manipulative mechanism is known, or because the behavioural change is so complex and spectacular that alternative explanations do not apply (see e.g. Moore \& Gotelli, 1990; Poulin, 1995). In most cases, however, it is difficult to ascertain (i) whether the behavioural change is a parasite adaptation or just non-adaptive side-effects/pathology following infection (ii) whether the parasite or the host benefits from the change or (iii) whether the behavioural change is a product of natural selection in the given host-parasite association or merely represents a phylogenetic constraint that may or may not be adaptive to the parasite in the present system (Moore \& Gotelli, 1990; Poulin, 1995). However, there exists also another immediately testable hypothesis

* Tel: + 643476 7987. Fax: + 643479 7584. E-mail: kim.mouritsen@stonebow.otago.ac.nz that ought to be, but rarely is, considered in studies of parasite-induced behavioural change: that the recorded unusual behaviour of the infected host is not parasite-induced. The association between altered behaviour and the occurrence of parasites might well be a secondary event in which the parasite preferentially infects hosts that, for various reasons other than parasites, express a behaviour different from average.

The echinostomid digenean Curtuteria australis is common in soft-bottom intertidal habitats in New Zealand (Allison, 1979; Thomas \& Poulin, 1998; personal observation). It uses the mud flat whelk Cominella glandiformis as first intermediate host from which the free-swimming cercariae emerge in order to penetrate and encyst in the foot of the second intermediate host, the New Zealand cockle Austrovenus stutchburyi, that acquire them through the filtration current. The final hosts are oystercatchers that feed on the cockles during low tide. In a previous study, Thomas \& Poulin (1998) demonstrated a negative relationship between foot length and Curtuteria load in cockles and showed that heavily infected individuals were unable to reburrow, probably because of their small foot, if dislodged to the sediment surface. This surfacedwelling behaviour was interpreted as an adaptive parasite-induced behavioural change with the outcome of increasing the rate of trophic transmission to 
the final hosts. Lying exposed on the flats at low tide, the cockles seemed easy prey for feeding shorebirds and Thomas \& Poulin (1998) also showed experimentally that cockles that were unable to burrow were actually preyed upon to a larger extent than individuals able to burrow. They did not, however, test the alternative hypothesis that cockles, caught on the surface for reasons other than parasites, might accumulate parasites at a higher rate than buried ones thereby giving rise to a positive association between surface-dwelling and high parasite intensity. If so, the surface-dwelling behaviour of heavily infected Austrovenus may not be parasite induced.

On intertidal flats of southern New Zealand, cockles are frequently caught on the sediment surface for an extended period of time due to foot-cropping (K. N. Mouritsen, unpublished data). Particularly on sites where significant bioturbators, such as ghost shrimps Callianassa filholi, mud shrimps Upogebia danai or lugworms Abarenicola assimilis, occur in high density, cockles are forced into frequent relocation in order to avoid being buried deeply beneath the sediment surface. During crawling, however, the foot of the cockle is very often cropped presumably by fish feeding on the flats at high tide, resulting in impaired burrowing ability for weeks until the foot has regenerated (K. N. Mouritsen, unpublished data). Together with a higher rate of parasite accumulation in surfaced than in buried cockles, this would provide a coherent alternative explanation to the observation of short-footed, heavily infected cockles unable to burrow into the substrate.

The aims of the present study were (1) to test the hypothesis that metacercariae of Curtuteria accumulate at different rates in surfaced and buried cockles under field conditions, and (2), to provide data on the trematode's selection of microhabitat within the cockle-foot that, by rejection of the above hypothesis, may help identify the mechanism by which the parasites interfere with the burrowing ability of cockles.

\section{MATERIALS AND METHODS}

\section{Collection of animals and design of field experiment}

Cockles were collected in January 1999 within a $2 \times 3 \mathrm{~m}$ site on a sand flat at Otakou on the southern shore of Otago Harbour, South Island. The infection intensity of $C$. australis was known to be low at that site. Sixty similarly sized cockles were selected, brought to the laboratory and placed in an outdoor aquarium supplied with fine sand as a substrate and running seawater. The following day it was confirmed that all cockles had burrowed and were filtering. The cockles were then divided into 3 groups (20 in each) by selecting individuals at random one at a time. One group ('before-cockles') was subsequently measured and dissected, providing a baseline for comparisons with 'surfacers' and 'burrowers' (see below). The cockles from the 2 remaining groups were established individually in mesh-cages placed $3.5 \mathrm{~km}$ from the site of collection on a $340 \mathrm{~m}$ wide, homogeneous intertidal sand flat at Lower Portobello, Otago Harbour. Here the intensity of trematode infection in the local cockles was known to be relatively high. The 40 cages were placed $1 \mathrm{~m}$ apart on a straight line parallel to, and $80 \mathrm{~m}$ landward from the mean low water line. The cages were cylinders $(14 \mathrm{~cm}$ high, $8 \mathrm{~cm}$ in diameter) made of plastic-mesh (mesh size : $16 \times 20 \mathrm{~mm}$ ). Each cage was pushed $9 \mathrm{~cm}$ into the sediment, leaving $5 \mathrm{~cm}$ above the surface, and the sediment inside the cages was cleared of local cockles. Every second cage was then equipped with a mesh-floor (same mesh type) placed just at the sediment surface, effectively preventing the cockles from burrowing into the sediment. After establishment, all cages were closed at the top (same mesh type), and left for 62 days (collected end of March). During this period, the experimental site was visited regularly in order to ensure that cages and cockles were in place, that cockles allowed to burrow actually did so, and to remove macroalgae occasionally caught on the cages.

A systematic experimental design (i.e. alternating surfacers and burrowers) was chosen in preference to complete randomization in order to avoid the possibility of chance clustering of treatments along the $39 \mathrm{~m}$ long experimental site (see Krebs, 1999). Although the intertidal flat appeared very homogeneous, a small unrecognized gradient e.g. in hydrodynamic conditions, could in principle affect the rate by which the cockles accumulated parasites.

\section{Variables measured during dissection}

Although the 60 cockles were grouped at random, chance events might nevertheless produce uneven groups according to a range of non-treatment factors potentially important either to the rate of Curtuteria accumulation during the experiment or to the preexperimental parasite load. Hence, also the shell length, age, gender, reproductive stage, foot size, incidence of foot cropping, condition factor, occurrence of the ectoparasitic spionid polychaete Boccardia acus and abundance of other macroparasites present were recorded for each individual cockle. It could then be established whether or not burrowers and surfacers, in particular, differed with respect to those factors. Occurrence of parasites has previously been shown to vary according to size, age, reproductive stage and the general condition in bivalves (e.g. Lauckner, 1983), and sex-biased infection intensity has been reported in a range of taxa (e.g. Poulin, 1996; Wedekind \& Jacobsen, 1998). This could be relevant also to cockles. As the basic substrate for cercarial invasion, the size of the foot might affect the trematode's settling success. Like- 
wise, since the foot of Austrovenus frequently is cropped this will affect the foot area, and newly regenerated foot tissue might also differ from old tissue regarding susceptibility to infection. The occurrence of spionid polychaetes that live in burrows excavated in the shell is known to affect the condition of bivalves negatively (e.g. Lauckner, 1983; Wargo \& Ford, 1993) perhaps influencing, in turn, parasite accumulation. Finally, since different parasite species sharing the same host species often co-occur more frequently than expected by chance (e.g. Poulin, Steeper \& Miller, 2000), the presence of other parasites in the cockles might influence the rate at which Curtuteria accumulates.

Data on age, incidence of foot cropping, and condition factor were not obtained from the group of cockles dissected prior to the field experiment ('before-cockles').

\section{Size and age}

Prior to dissection, the maximum shell length was measured and the number of growth interruption lines on the shell was determined as a measure of cockle age. It is unclear whether the number of interruption lines identified is equal to the number of years. However, the number of lines will correlate strongly with age, and hence, be useful in the present comparative context.

\section{Metacercarial counts and foot measurements}

The cockles were opened by cutting their 2 adductor muscles. The foot was removed by cutting along the narrow 'neck' between the gonad and foot basis. Then the length of the foot was measured along the outer rim (from the tip to the hindmost end). The foot was placed between 2 slides and the numbers of C. australis metacercariae were counted - they were easily identified through the transparent foot tissue. It was noted whether the foot showed signs of having been cropped, recognized by an uneven foot rim and the presence of lighter, newly regenerated foot tissue. The foot was blotted by tissue paper (once on each side) to remove excess water, and the wet-weight was measured.

In order to determine the distribution of parasites within the foot, the numbers of metacercariae were recorded from 3 different foot sections (tip, mid part and hind part) on 13 burrowers and 12 surfacers. The section borders were established on the basis of 3 evenly long parts of a tangent to the outer foot-rim from the tip to the hindmost part (see Fig. 2). Since a cockle foot is approximately triangular in shape when relaxed, the surface-areas of the 3 footsections were of uneven size. In order to correct for this, and hence achieve a measure of parasite density, the average size of the 3 foot sections was obtained from the projected area $\left(\mathrm{mm}^{2}\right)$ of 10 randomly chosen cockle feet.

\section{Sex and reproductive stage}

The cockles were sexed on the basis of gametes if present, and the developmental stage of the gonad was established by scoring ( 0 : undeveloped, no sexual products identified; 1 : little developed with few immature sexual products; 2: well-developed with few mature sexual products; 3 : fully developed with mature eggs or sperm; 4 : spent gonad with few sexual products left). These scores are inevitably subjective. However, because (a) all 40 experimental cockles were processed on the same day, (b) no $a$ priori assumption of difference between the groups of cockles was made, and (c) the different treatment groups were dissected randomly, the results are considered reliable.

\section{Other parasites or symbionts}

During dissection, attention was paid to the presence of other parasites or symbionts known to be present in the population of Austrovenus in Otago Harbour (personal observation). These included Meiogymnophallus sp., Cercaria pectinata (probably Fellodistomidae), pea crabs (Pinnotheres sp.) and the polychaete $B$. acus. The amount of shell damage caused by $B$. acus was scored $(0$ : no attack; 1 : light attack [i.e. one burrow] on one or both valves; 2 : heavy attack [i.e. more than one or a branched burrow] on one valve and no or light attack on the other; 3 : heavy attack on both valves).

\section{Condition factor}

The soft tissue of each cockle was removed from the shell and placed together with the foot in preweighed cups and left at $70{ }^{\circ} \mathrm{C}$ for $24 \mathrm{~h}$. Then the weight of the cup plus contents was determined and the soft-tissue dry-weight $(S T D W)$ could be calculated. The $S T D W$ values $(\mathrm{mg})$ were used to calculate the condition factor $(C F)$ according to the formula $C F=100 \times S T D W / L^{\mathrm{b}}$, where $L$ is the shell length $(\mathrm{mm})$ and $\mathrm{b}$ is the regression coefficient for the relationship between $\ln (S T D W)$ and $\ln (L)$ across the entire material. This regression was statistically significant $\left(F_{1,38}=23.4, P<0.001\right)$ with a regression coefficient $\mathrm{b}=2 \cdot 272$.

\section{Foot mobility}

In order to investigate the relationship between the ability of the foot of the cockle to contract as a function of infection intensity, additional cockles were collected from sites known to support individuals with different levels of infection intensity. In total 37 cockles of approximately similar size (length range: $27 \cdot 0-33 \cdot 2 \mathrm{~mm}$ ) were collected and dissected alive. Immediately after opening, the length of the foot was measured using a calliper (contact with the foot-tissue was avoided as far as possible). The foot 


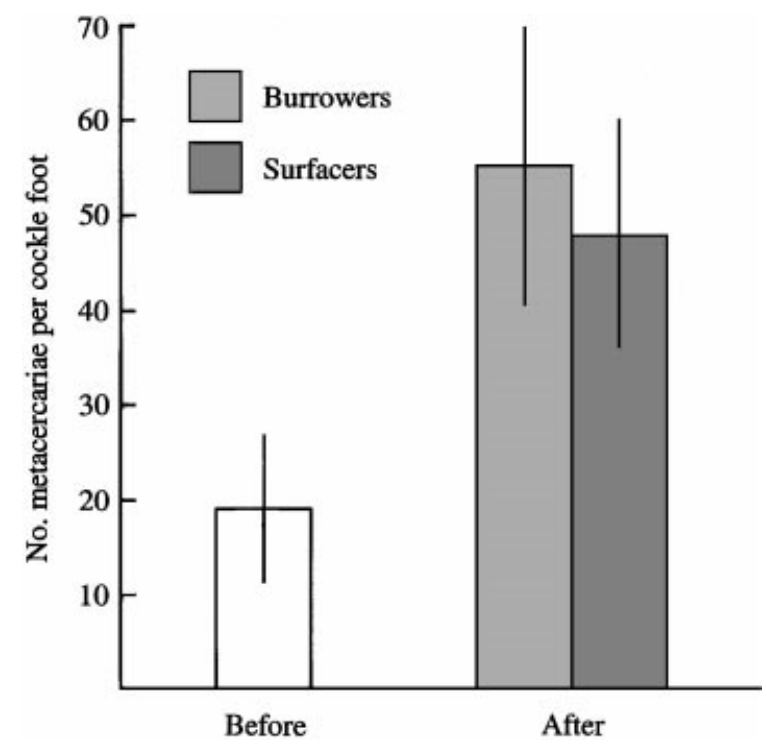

Fig. 1. The infection intensity by Curtuteria australis metacercariae in the 3 groups of cockles (mean number of cysts per cockle foot \pm s.D.; $n=20$ for all values). Before: cockles dissected before the experiment. After: cockles dissected after the experiment during which burrowers were allowed to burrow into the sediment while surfacers were prevented from burrowing, lying on the sediment surface.

was then tapped 4 times by the blunt end of a pair of tweezers, and the foot-length was re-measured after $5 \mathrm{sec}$. The foot was then removed and the number of metacercariae determined.

\section{Data analysis}

Application of multivariate analysis was considered inappropriate because of the experimental design and the relatively small sample size in combination with several measured variables (many potential interactions). Hence, each variable was considered separately. The statistical analysis was carried out in SPSS (Statistical Package for the Social Sciences) initially using standard parametric tests. Whenever assumptions of normality and homogeneity of variance were violated, or the nature of the data required it, analysis was performed on square-root or lntransformed data, or non-parametric tests were applied. Pair-wise post hoc tests following parametric main analysis were carried out using Bonferroni test, thereby correcting for multiple comparisons.

\section{RESULTS}

\section{Intensity of Curtuteria infections}

The 3 groups of cockles differed significantly regarding mean intensity of Curtuteria metacercariae (one-way ANOVA, $F_{2,57}=64 \cdot 3, P<0.001$ ), due to a significantly higher intensity in the 2 experimental groups (burrowers and surfacers) than in beforecockles $(P<0.001$ for both, Fig. 1). Although burrowers on average harboured approximately $14 \%$ more metacercariae than surfacers the difference was not statistically significant $(P=0 \cdot 38)$. Considering burrowers and surfacers together, the infection intensity increased almost 3-fold during the 62-day experimental period. This corresponds to an average accumulation rate of 0.5 metacercaria per day.

\section{Potentially interacting variables}

No significant difference could be demonstrated among the 3 groups regarding shell length, polychaete attack or infection intensity of Meiogymnophallus sp. (Table 1). No other species of parasite were encountered. Moreover, burrowers and surfacers did not differ significantly regarding age, incidence of foot-cropping or condition factor (Table 1). Taking burrowers and surfacers together, the post-experimental parasite intensity did not differ between individuals that had been foot-cropped prior to the experiment (mean \pm s.D.: $54 \cdot 1 \pm 15 \cdot 4$ ) and those that had not $(49 \cdot 1 \pm 11 \cdot 7$; Student's $t$-test, $\left.t_{38}=1 \cdot 16, P=0 \cdot 25\right)$.

The proportion of males was close to significantly different among groups. This was mainly due to the high frequency of males among before-cockles because the (also quite large) difference between the 2 experimental groups was far from significant (Table 1). However, no statistical difference was found between males and females in mean intensity of metacercariae either among burrowers (Student's $t$-test, $\left.t_{17}=1.62, P=0.13\right)$ or surfacers $\left(t_{14}=1 \cdot 09\right.$, $P=0 \cdot 30$ ), suggesting that the slight sex bias between the 2 experimental cockle-groups was unlikely to have affected the rate of parasite accumulation.

The reproductive stage of the cockles changed during the experiment from fully developed gonads with mature sexual products (the before-cockles) to spent gonads (the experimental cockles, Table 1). No difference in gonad development was recognized between burrowers and surfacers.

Both the length and the wet weight of the cockle foot differed significantly among groups (Table 1). Surfacers had the longest foot on average, being significantly longer than the before-cockles $(P<0.002)$ but not significantly longer than the feet of burrowers $(P<0.098)$. The foot length of beforecockles and burrowers did not differ $(P=0 \cdot 50)$. No significant difference could be demonstrated in foot weight between before-cockles and burrowers $(P=$ $0 \cdot 27)$, whereas surfacers had significantly heavier feet than both burrowers (Table 1) and, in particular, before-cockles $(P<0 \cdot 001)$.

Among burrowers as well as surfacers, no significant relationship was found between the intensity of metacercariae and foot length or weight $\left(\left|r_{\mathrm{s}}\right|<0 \cdot 13, n=20, P>0.58\right)$. It should be emphasized that this latter statement cannot be taken as contra-evidence for the negative relationship be- 
Table 1. Values obtained on the different variables measured on cockles before and after the field experiment

(Burrowers: cockles allowed to burrow into the sediment; surfacers: cockles prevented from burrowing. Note that 'before' and 'after' does not imply repeated measurements. If not otherwise stated, values are mean (s.D.) or median [interquartile range]. $n=20$ for each value but sex ratio (burrowers: $n=19$; surfacers $n=16) . P_{1}: P$-value for statistical test including all 3 groups of cockles; $P_{2}: P$-values for 2 -sample test on the experimental groups ('after') only.)

\begin{tabular}{|c|c|c|c|c|c|}
\hline \multirow[b]{2}{*}{ Variable } & \multirow[b]{2}{*}{ Before } & \multicolumn{2}{|l|}{ After } & \multirow[b]{2}{*}{$P_{1}$} & \multirow[b]{2}{*}{$P_{2}$} \\
\hline & & Burrowers & Surfacers & & \\
\hline Shell length (mm) & $29 \cdot 9(0 \cdot 8)$ & $30 \cdot 3(1 \cdot 0)$ & $30 \cdot 1(1 \cdot 0)$ & $0 \cdot 40^{*}$ & \\
\hline Age (no. interruption lines) & & $9 \cdot 9(2 \cdot 8)$ & $10 \cdot 2(2 \cdot 4)$ & & $0 \cdot 71 \uparrow$ \\
\hline Sex ratio ( $\%$ males $)$ & $70 \cdot 0$ & $52 \cdot 6$ & $31 \cdot 3$ & $0 \cdot 07 \ddagger$ & $0 \cdot 35 \ddagger$ \\
\hline Gonad development (score) & $3 \cdot 0[0]$ & $4 \cdot 0[0]$ & $4 \cdot 0[0]$ & $0 \cdot 001 \ddagger$ & $0 \cdot 27 \ddagger$ \\
\hline Foot length $(\mathrm{mm})$ & $12 \cdot 8(0 \cdot 6)$ & $13 \cdot 2(0 \cdot 8)$ & $13 \cdot 7(0 \cdot 8)$ & $0 \cdot 003^{*}$ & $0 \cdot 098 \S$ \\
\hline Foot weight (mg wet-weight) & $46 \cdot 4(6 \cdot 4)$ & $51 \cdot 2(9 \cdot 2)$ & $61 \cdot 0(9 \cdot 6)$ & $0 \cdot 001 *$ & $0 \cdot 005 \S$ \\
\hline Foot cropping ( $\%$ cropped $)$ & & $60 \cdot 0$ & $40 \cdot 0$ & & $0 \cdot 34 \ddagger$ \\
\hline Condition factor & & $10 \cdot 2(0 \cdot 9)$ & $10 \cdot 1(1 \cdot 1)$ & & $0 \cdot 61 \uparrow$ \\
\hline Polychaete attach (score) & $2 \cdot 0[0 \cdot 75]$ & $2 \cdot 0[0]$ & $2 \cdot 0[1 \cdot 0]$ & $0.65 \ddagger$ & \\
\hline Meiogymnopallids $(n)$ & $4 \cdot 0[5 \cdot 0]$ & $3 \cdot 5[5 \cdot 3]$ & $4 \cdot 0[7 \cdot 5]$ & $0 \cdot 58 \mathbf{9}$ & \\
\hline
\end{tabular}

* One-way ANOVA.

$\dagger$ Student's $t$-test.

† Two-way contingency table $/ \chi^{2}$-test.

$\S$ Bonferroni post-hoc test.

g Kruskall-Wallis test.

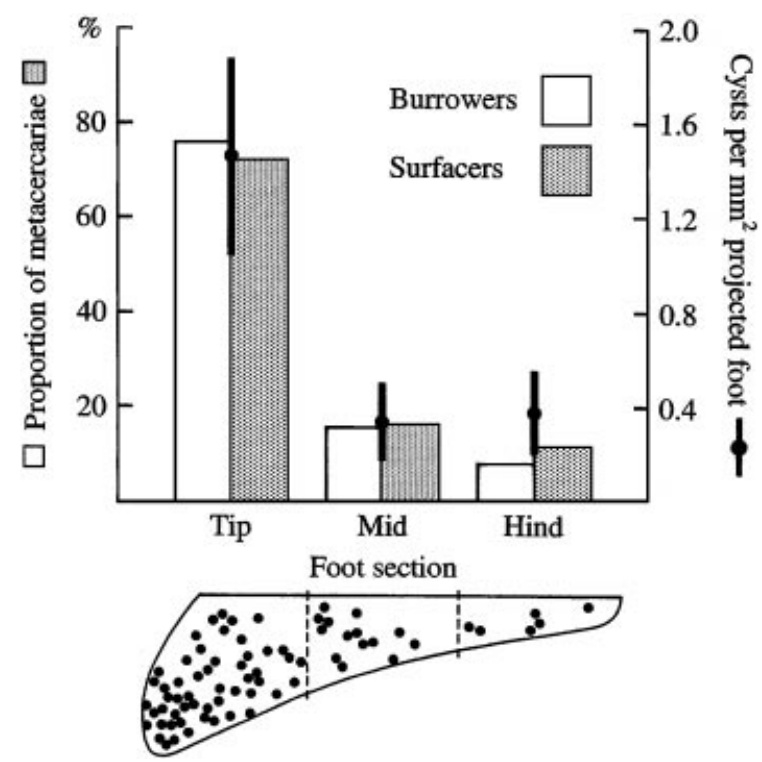

Fig. 2. The distribution ( $\%$ ) and density (mean number of cysts per $\mathrm{mm}^{2}$ projected foot \pm s.D. ; burrowers and surfacers combined) of Curcuteria australis metacercariae along the foot of the experimental cockles. Below: outline of cockle foot showing the approximate footsection boarders and metacercariae $(\mathbf{O})$.

tween relative foot-size and Curtuteria load reported by Thomas \& Poulin (1998).

\section{Microhabitat selection in Curtuteria}

The distribution of metacercariae within the cockle foot did not differ significantly between burrowers and surfacers (two-way contingency table, $\chi_{2}^{2}=4 \cdot 82$,

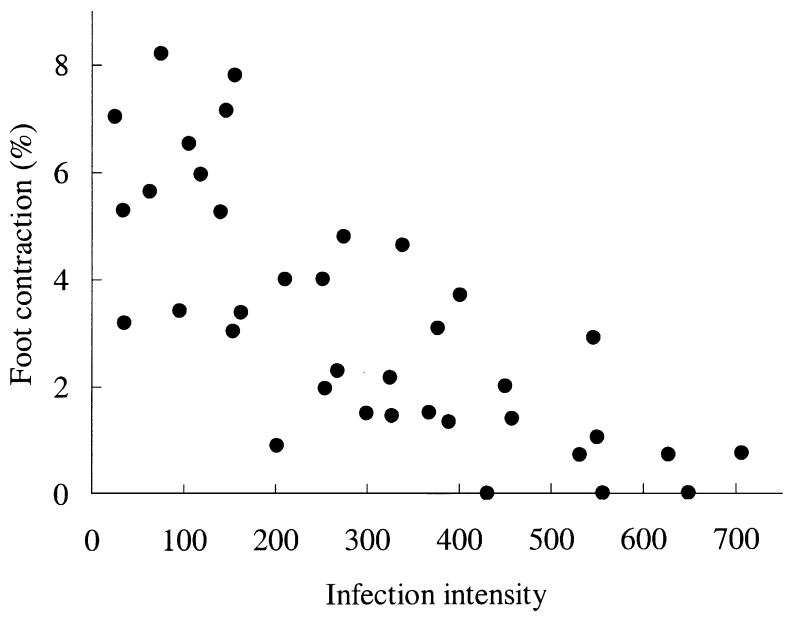

Fig. 3. The relationship between relative foot contraction (percentage foot length reduction following mechanical stimulation) and the infection intensity by Curtuteria australis metacercariae.

$P<0 \cdot 09, n=1217$, Fig. 2). However, the parasites were not evenly distributed along the foot (Fig. 2). The vast majority was found in the tip of the foot in both burrowers $\left(\chi_{2}^{2}=579 \cdot 5, P<0 \cdot 001, n=691\right)$ and surfacers $\left(\chi_{2}^{2}=360 \cdot 0, \quad P<0 \cdot 001, \quad n=526\right)$. This pattern was clearly evident also when parasite numbers in each foot section were corrected for the projected foot-area (burrowers and surfacers combined; Friedman test, $\chi_{2}^{2}=38.5, P<0 \cdot 001, n=25$, Fig. 2). Considering burrowers and surfacers together, the density of larval trematodes was almost 4 times greater in the tip of the foot than in each of the 2 remaining foot-sections. 


\section{Infection intensity and foot contraction}

A highly significant and negative relationship could be demonstrated between the relative reduction in foot length following mechanical disturbance and the infection intensity $\left(r^{2}=0 \cdot 57, n=37, P<0 \cdot 0005\right.$, Fig. 3). This suggests that the presence of metacercariae seriously interfere with the ability of the foot to contract.

\section{DISCUSSION}

The 3-fold increase in the cockle's load of Curtuteria metacercariae during the experiment, demonstrates that the cockle-transplantation succeeded in its attempt to accelerate parasite accumulation thereby achieving an infection intensity significantly above the background level. The result that surfaced cockles did not attain a higher load of metacercariae than buried individuals is therefore valid. Before it can be concluded that Curtuteria larvae accumulate with a similar rate in buried and surfaced cockles, everything else being equal, the potentially interacting factors must be considered. However, neither cockle size, age, sex ratio, incidence of foot-cropping, polychaete attack or infection by meiogymnophallids differed significantly between treatments and was hence unlikely to have affected the main result. Moreover, forcing the surfacers onto the sediment surface for an extended period of time seemed not to affect their general 'well-being' severely. Surfacers and burrowers could be assigned the same condition factor at the end of the experiment, and both groups spawned during the experiment, reaching a common median gonad development score. The latter suggests that the reproductive cycle of surfacers was largely unaffected by the treatment. The only significant divergence between burrowers and surfacers, with potential importance for the interpretation of the accumulation rates, is the difference in foot size. Although the tendency of longer feet among surfacers was non-significant, they did attain a significantly heavier foot than burrowers during the experiment. One possible explanation for this is exercise. The post-experimental parasite load was low in comparison with cockles whose feet were found to be significantly affected by Curtuteria at other sites in Otago Harbour (about 100-1000 metacercariae per specimen, Thomas \& Poulin, 1998), and the mobility of the experimental cockles was apparently little affected (see also Fig. 4). Forced to stay at the sediment surface by the design of the cages, the surfacers may, during the 2-month experiment, repeatedly have attempted to burrow into the sediment below the mesh floor, thereby exercising their foot. Nevertheless, since there was no significant relationship between the foot measurements and Curtuteria intensity after experimentation, the difference between the 2 cockle groups is unlikely to have affected the accumulation rate of metacercariae to any great extent.

Because none of the variables measured either differed between treatments or seemed to relate to the recorded infection intensity, the lack of significant difference in the post-experimental load of metacercariae between surfacers and burrowers suggests that the coincidence of high metacercariae intensity and surfacing behaviour in some populations of Austrovenus (Thomas \& Poulin, 1998) is not a secondary event: Curtuteria is unlikely to be engaged in a strategy of hitch-hiking surfaced cockles in preference to buried specimens (for instance due to a specific cercarial behaviour). The present study therefore indirectly supports Thomas \& Poulin (1998) who suggested that heavily infected cockles are manipulated by the parasites in order to prevent them from re-burrowing if dislodged to the sediment surface, in turn increasing the likelihood of trophic transmission to the final host.

\section{Potential manipulative mechanisms}

Thomas \& Poulin (1998) suggested that Curtuteria reduced the growth of the cockle foot and the resulting small foot was the proximal cause preventing heavily infected specimens from burrowing. Based on regression lines on the relationship between the relative foot length (foot length corrected for cockle size) and metacercariae load from the 3 sites investigated by Thomas \& Poulin (1998), the foot of infected cockles was on average reduced by $6-18 \%$ (12-30\% for the most heavily infected specimens). Whereas such reductions likely prolong the process of burrowing, it is questionable whether they will prevent the animal from burrowing altogether unless in the most extreme cases.

An alternative manipulative mechanism can be inferred from the distribution of metacercariae within the cockle-foot (primarily in the tip) and the way this may interact with the function of the burrowing apparatus in bivalves (see Fig. 4). Hence, the metacercariae can be envisaged to interfere mechanically with the first 2 phases of burrowing (Fig. 4A,B) in particular: they may obstruct proper functioning of the transverse muscles making the foot unable to become narrow and elongated. This may be evident particularly in the tip of the foot due to its relatively high density of metacercariae, and a relatively bulbous foot-tip may effectively hamper the foot from penetrating the substrate. The high cyst abundance in the foot-tip may also obstruct the flow of haemolymph to this part, preventing the foot from being anchored in the substrate. When the longitudinal (retractor) muscles are activated (Fig. $4 \mathrm{C}$ ), the foot will be retracted rather than the shell being pulled in. Finally, because Curtuteria is distributed not only in the tip but along the entire foot, the functioning of the retractor muscles may 


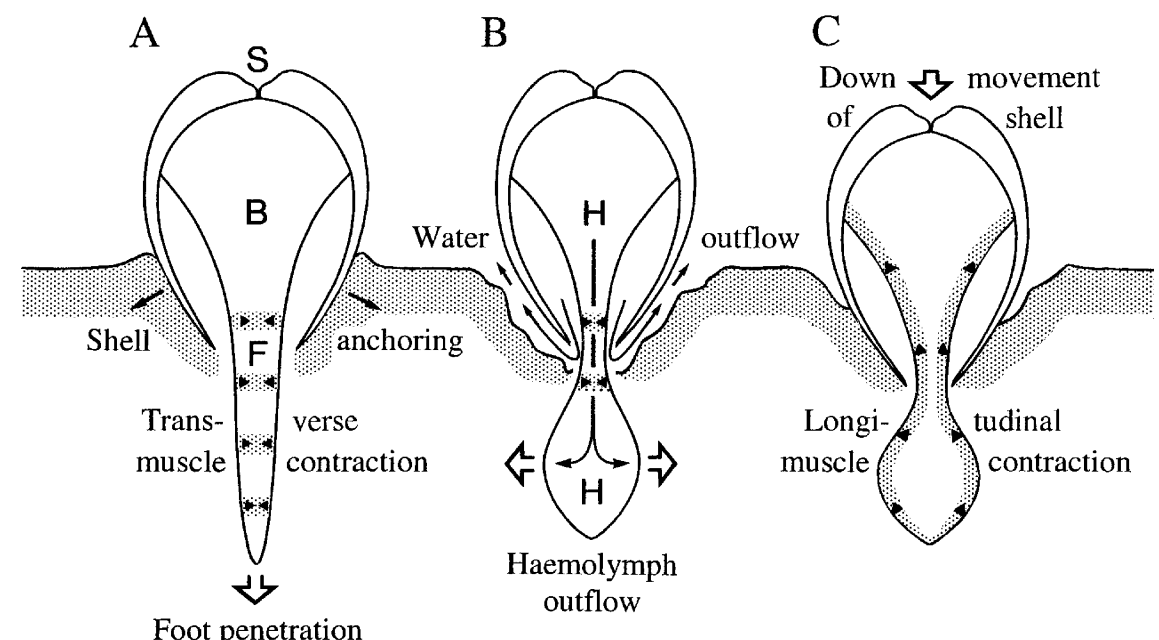

Fig. 4. The sequence of burrowing in a bivalve. S, shell; B, main body; F, foot; H, haemolymph; horizontal shading with arrows: transverse muscle contraction; vertical shading with arrows: longitudinal (retractor) muscle contraction. (A) The valves are pressed against the substrate, thereby anchoring the shell. By contracting the transverse muscles (and the action of protractor muscles), the foot becomes narrow and elongated causing it to penetrate the substrate. (B) Haemolymph is squeezed into the distal end of the foot, where the transverse muscles now are relaxed, causing it to become bulbous, and hence, anchoring it in the substrate. At the same time water is pressed out of the mantel cavity in order to loosen the shell from the sediment. (C) The retractor muscles that run from the shell to the tip of the foot contract, and the shell is pulled deeper into the substrate. Modified and simplified after Alexander (1979) and Barnes (1980).

also be significantly affected over a longer stretch. This is strongly supported by the negative relationship between the ability of the foot to contract and infection intensity. In concert, these interactions may cause the foot of heavily infected cockles to be literally immobilized. Under the assumption that immobilized muscle tissue tends to degenerate, the smaller foot of heavily infected cockles should perhaps be viewed merely as a side-effect of the parasites' primary manipulation strategy. However, a small foot will by no means make burrowing easier for the cockles.

The high cyst abundance in the distal end of the foot may be the key to the mechanism of manipulation; this is supported by observations on the European cockle Cerastoderma edule and its parasites. Among the different species of echinostomids that commonly infect $C$. edule, Himasthla elongata is the only species that is found predominantly in the foottip and the only one found to significantly impair burrowing in the cockle (Lauckner, 1983).

The pattern of parasite distribution along the cockle-foot may be accomplished by a combination of the cercarial behaviour and the way in which the foot is positioned in a burrowed cockle. Similar to European species of echinostomids, for instance $H$. elongata (Werding, 1969; Lauckner, 1983 ; Montaudouin et al. 1998; personal observation), released Curtuteria-cercariae swim very close to the surface of the substrate (Allison, 1979). As it seems to be the case also for other species of cercariae infecting bottom-dwelling hosts, this may stem from positive geotaxis and/or negative phototaxis (Lauckner, 1983; Ginetsinskaya, 1988; Montaudouin et al.
1998; Mouritsen, 2001). This suggests that Curtuteria cercariae, after entering the cockles via the inhalant siphon, will accumulate in the bottom part of the mantle cavity and predispose the tip of the foot to infestation due to its location also in this part of a buried cockle. The pattern may be reinforced by the fact that the foot-tip is the most prominent obstacle the cercariae meet on their way through the inhalant chamber of the cockle, and that cercariae caught in the gills likely will be deposited together with the other pseudofaeces in the bottom of the mantle cavity (e.g. Barnes, 1980). Together, these processes may provide a coherent interpretation of the high density of metacercariae in the foot-tip that rapidly levels off to a common low density in the mid and hind part of the cockle-foot.

The work was supported by a grant from The Carlsberg Foundation (Denmark). During preparation of the manuscript, support was provided by The Danish Natural Science Research Council and the Marsden Foundation (New Zealand). I also wish to thank Robert Poulin and the referees for useful comments on an earlier draft, and the staff of Portobello Marine Laboratory for invaluable technical support.

\section{REFERENCES}

ALEXander, R. M. (1979). The Invertebrates. Cambridge University Press, Cambridge.

ALlison, F. R. (1979). Life cycle of Curtuteria australis n.sp. (Digenea: Echinostomatidae: Himasthlinae), intestinal parasite of the South Island pied oystercatcher. New Zealand Fournal of Zoology 6, 13-20. 
BARNES, R. D. (1980). Invertebrate Zoology, 4th Edn. Saunders College, Philadelphia.

ginetsinskaya, T. A. (1988). Trematodes, Their Life Cycles, Biology and Evolution. Amerind Publishing Co. Pvt. Ltd, New Delhi.

Krebs, C. J. (1999). Ecological Methodology, 2nd Edn. Addison-Wesley Educational Publishers, California.

LAUCKNer, G. (1983). Diseases of Mollusca: Bivalvia. In Diseases of Marine Animals, vol. 2 (ed. Kinne, O.), pp. 477-879. Biologische Anstalt Helgoland, Hamburg.

montaudouin, X. De., Wegeberg, A. M., Jensen, K. T. \& SAURIAU, P. G. (1998). Infection characteristics of Himasthla elongata cercariae in cockles as a function of water current. Diseases of Aquatic Organisms 34, 63-70.

Moore, J. \& Gotelli, N. J. (1990). Phylogenetic perspective on the evolution of altered host behaviours: a critical look at the manipulation hypothesis. In Parasitism and Host Behaviour (ed. Barnard, C. J. \& Behnke, J. M.), pp. 193-233. Taylor and Francis, London.

MOURITSEN, K. N. (2001). Hitch-hiking parasite: a dark horse may be the real rider. International Fournal for Parasitology 31, 1417-1420.
POUlin, R. (1995). 'Adaptive' changes in the behaviour of parasitized animals : a critical review. International Fournal for Parasitology 25, 1371-1383.

POUlin, R. (1996). Sexual inequalities in helminth infections: a cost of being a male? American Naturalist 147, 287-295.

POUlin, R., STEEPER, M. J. \& Miller, A. A. (2000). Nonrandom pattern of host use by the different parasite species exploiting a cockle population. Parasitology 121, 289-295.

THOMAS, F. \& POULIN, R. (1998). Manipulation of a mollusc by a trophically transmitted parasite: convergent evolution or phylogenetic inheritance? Parasitology 116, 431-436.

WARGO, R. N. \& FORD, S. E. (1993). The effect of shell infestation by Polydora sp. and infection by Haplosporidium nelsoni (MSX) on tissue condition of oysters, Crassostrea virginica. Estuaries 16, 229-234.

WEDEKind, C. \& JACOBSEN, P. J. (1998). Male-biased susceptibility to helminth infection: an experimental test with a copepod. Oikos 81, 458-462.

WERDING, B. (1969). Morphologie, Entwicklung und Ökologie digener Trematoden-larven der Strandschnecke Littorina littorea. Marine Biology 3, 306-333. 